and at the same time the most complete, is further illustrated by seven large folding lithographed plates. These are bound at the end of the volume.

Suffice it to say that this piece of work is a matter for congratulation to Prof. Disselhorst, and its publication a credit to all concerned.

Francis H. A. Marshall.

\section{SPECTRUM ANALYSIS.}

An Introduction to the Study of Spectrum Analysis. By W. Marshall Watts, D.Sc., F.I.C. Pp. vii+ 325. (London: Longmans, Green and Co., I904.) Price ros. $6 d$. net.

$\mathrm{T}^{\mathrm{T}}$ is somewhat remarkable that, in spite of the great interest and importance of the subject, there are few, if any, text-books on spectrum analysis which really meet the requirements of beginners who desire to take up the matter practically. The announcement of an introductory work by the wellknown compiler of the "Index of Spectra," however, led to the hope that this gap in the literature of the spectroscope would at last be adequately filled, but it is disappointing to find that the needs of the practical student are again almost disregarded.

The book includes a brief account of the optical principles underlying the different forms of spectroscope, and general explanations of the methods of producing and mapping spectra, besides which there are short statements relating to the arrangement of lines in series, and the applications of the spectroscope to the study of the heavenly bodies. When it is stated that nearly half the book is occupied by wave-length tables, and that there are 135 illustrations-many of them large ones-it will be seen that the general treatment can scarcely be otherwise than sketchy. The descriptions of the modes of procedure are consequently often lacking in details which would have been of the greatest use to the student. Thus, with reference to the spectra of gases, the only method of observation indicated is that of a readymade Geissler tube, which, as the author remarks, does not always show the spectrum of the gas present in the greatest proportion; it would have been useful to explain how the student might examine the spectrum of a gas collected or prepared by himself. Later on, there is a short account of stellar spectra, but no directions whatever as to how such a spectrum may be observed.

Another very serious defect from the student's point of view is the use of the arbitrary scale of Bunsen in the maps and earlier descriptions of the characteristic lines of the different elements. It is afterwards shown how such measurements may be reduced to wave-lengths, but surely it would have been better to define the various lines by their wavelengths from the very beginning; as it stands, a great deal of unnecessary labour is involved in the comparison of the descriptions and maps with the wave-length tables given at the end of the book.

The book, in fact, leaves a great deal to be NO. I 824 , VOL. 7O] desired, whether considered as a laboratory guide or as a descriptive work. Many important facts are left unnoticed, though space might have been found for some of them by the omission of superfluous or insufficiently described illustrations. In the section on nebulæ, for instance, there are no less than eight diagrams showing the telescopic appearances of these objects, but no reference to the fact that all nebulæ do not exhibit bright line spectra; the reader is, moreover, likely to get the wrong impression that the chief nebular line is due to nitrogen.

Though brought well up to date in some respects, the book is far behind the times in others. It is erroneously stated (p. 106) that the spectrum of the solar corona includes lines of helium, hydrogen, and calcium, and the important subject of enhanced lines in relation to many celestial spectra is overlooked altogether.

Many other examples of the shortcomings to which attention has been drawn might be given, but the above will sufficiently indicate that the selection of material has not been judiciously made. By far the most valuable feature of the book is the series of abridged tables of wave-lengths, showing the more important lines in the spectra of nearly all the known chemical elements.

\section{OUR BOOK SHELF.}

Text-books of Physical Chemistry.-Electrochemistry. Part i. General Theory. By R. A. Lehfeldt, D.Sc. Pp. viii +268 . (London : Longmans, Green and Co., 1904.) Price $5 s$.

STUdents of physical chemistry have to-day no cause to complain of a dearth of books upon the subject. There are a considerable number of large volumes treating of this branch, and now we have the series of text-books edited by Sir William Ramsay. The book under review is the second of the series, and has been entrusted to Dr. Lehfeldt, who is well known as a worker on the physical side of electrochemistry.

Dr. Lehfeldt has not followed any hard or fast line laid down by previous writers upon the subject, and for this reason the book may be read with more than ordinary interest. The book is divided into three chapters, which might perhaps better be designated parts i., ii., and iii. Chapter ii. is written by $\mathrm{Mr}$. T. S. Moore, and deals with the relation of chemical constitution to conductivity. This chapter is very carefully thought out and arranged, and the author has consulted the latest literature. It deals, in the first place, with the relation of charge carried to constitution, this portion being really a repetition and enlargement of what has already been dealt with in the previous chapter. In fact, chapter ii. is to a certain extent an addendum to the first chapter, but it should in no wise be skipped by the student who desires to comprehend the bearing of electrochemistry on chemical problems. Other points treated in this chapter are relation of the number of ions in solution to constitution, pseudo acids and bases, amphoteric electrolytes, and so on.

Chapter i. commences with a description of certain voltameters. We would rather that the author had adopted the term coulommeter, because the instruments are for measuring current and not potential, 